\title{
Recent Progress in Biodegradable Polymers and Nanocomposites Based Packaging Materials for Sustainable Environment
}

\author{
Jolanta Wróblewska-Krepsztul ${ }^{1}$, Tomasz Rydzkowski ${ }^{*}$, Gabriel Borowski², Mieczysław \\ Szczypiński ${ }^{1}$, Tomasz Klepka ${ }^{3}$ and Vijay Kumar Thakur ${ }^{4 *}$
}

${ }^{1}$ Faculty of Mechanical Engineering, Koszalin University of Technology, Racławicka St. 1517, 75-620 Koszalin, Poland, Email: tomasz.rydzkowski@tu.koszalin.pl

${ }^{2}$ Faculty of Environmental Engineering, Lublin University of Technology, Nadbystrzycka St. 40B, 20-618 Lublin, Poland, Email: g.borowski@pollub.pl

${ }^{3}$ Faculty of Mechanical Engineering, Lublin University of Technology, Nadbystrzycka St. 36, 20-618 Lublin, Poland, Email: t.klepka@pollub.pl

${ }^{4}$ Enhanced Composites and Structures Center, School of Aerospace, Transport and Manufacturing, Cranfield University, MK43 0AL, UK, Email: vijayisu@,hotmail.com

\begin{abstract}
Plastics based materials are frequently used in packaging and can be seen universally in both the developed and developing societies. At present, most of the currently used food packaging materials are non-degradable and are creating serious environmental problems. New technologies are being explored and developed to study the complex interaction between the food packaging materials and food. For example, nanocomposite of cellulose constitute environmentally friendly packaging, which is easily recycled by combustion and requires low power consumption in production. There are several such biodegradable materials which are available at a low price, have good mechanical properties and allow disposal in the soil. This is advantageous because biological degradation produces only carbon dioxide, water, and inorganic compounds to name a few. It has also been discovered that biodegradable plastics made of such materials can be disposed of together with organic waste. The widespread use of biopolymers in place of standard plastics would help to reduce the weight of waste. Therefore, biodegradable materials take part in the natural cycle "from nature to nature" and play an important role for environmental sustainability. So in this article, we briefly summarizes the different characteristic of biodegradable polymers being used in food packaging applications.
\end{abstract} Keywords: Polymer; biodegradation; packaging materials; plastic; wastes. 


\section{Introduction}

Plastic waste, especially classic food packaging, is rapidly imposing a serious environmental problem around the globe[1]. In 2014, more than 7.5 million tons of plastic wastes were reported to be recycled[2]. In 2015, the plastics industry in Europe amounted to 49 million tons, of which $39.9 \%$ were packaged food products. Recently, there is a greater interest in the use of sustainable packaging materials as they are often functional and more environmentally friendly[3]. It has resulted in their share enhancement in the overall volume of plastic packaging. Different concerns especially environmental have led to an increased demand for use of biorenewable and biodegradable materials for packaging applications. Among different polymers currently being explored in this direction are those obtained from biorenewable sources (e.g. alginate, cellulose, chitosan, collagen carrageenan, corn zein, soy, starch etc) $[4,5]$. There is also a cumulative public interest in the use of biorenewable resources based biodegradable products in the food packaging sector, so as to reduce the amount of waste. The use of modern functional packaging materials is becoming increasingly popular as they are more environmentally friendly [6] [7].

Plastics are made of polymers which, in turn, can undergo a specific process of biodegradability depending upon their constituents[8]. Polymers decompose by biotic factors and also constitute a source of organic compounds (for example, monosaccharides, basic amino acids) for microorganisms (bacteria, algae, fungi) [9]. Microorganisms convert the polymers to the energy they need to live. The polymers during chemical processes get oxidized, leading to digestion in which the organic matter is converted to compound such as carbon dioxide[10]. The changes taking place during the degradation deteriorate the material for example leading to fragmentation. These changes are caused by the shortening of the polymer chain. The effects of shortening the polymer chains include shortening of the material, stretching, and breaking[11]. Fragmentation is the result of the distribution mechanism. In the next stage of decomposition, products are subjected to digestion by microorganisms. The degree of mineralization constitutes the basis for the final stage of biodegradation. The amount of evolved carbon dioxide as the process of respiration converts inorganic carbon to carbon dioxide. The closed system should have a suitable environment conductive to the proper functioning of the micro-organisms (temperature, $\mathrm{pH}$, humidity). There are many microbes that are capable of polymer biodegradation[12]. One such example, includes the fungus Phanerochaete chyrsosporium causing white rot of trees, degrading lignin in the presence of the enzyme catalysing the oxidation. Figure 1(a) summarizes the general properties required for food packaging materials[13]. 


\section{Polymers Based Packaging Materials}

\subsection{Plastics}

The first polymer based on cellulose appeared in 1856 and then phenol formaldehyde was discovered in 1907. Since that time, there has been several discoveries that have led to today's multitude of packaging materials made of synthetic and natural polymers[14-16]. In spite of the wider availability of synthetic materials, most of the industries including food and packaging industry are now considering the development of packaging materials from biorenewable resources as these are biodegradable [17, 18]. Figure 1(b) describes the life cycle of renewable biomass that includes water and $\mathrm{CO}_{2}$ production as well as conservation of fossil resources[8].

Improving safety and quality of food is the most important for consumers. Moreover, it is important that the coatings that are generally applied directly to the surface of food should be edible[19]. These coatings are provided with active compounds including antimicrobial agents and antioxidants, in order to achieve other desired effects[20]. Such coatings and packaging have the capability to protect well against microbial spoilage as well as loss of the actual quality of the product. A thin layer of edible coatings prepared from different edible materials having capability to act as a barrier to external elements (oil, moisture, steam), protect the goods and contribute to the shelf life. In order to cover fresh subscription of fruit and vegetables, a variety of products are used, e.g. wax, candy and nuts coated with shellac, a natural shield cover meat products and very common gelatin capsules for drugs[21]. Edible coatings offers many advantages: these can be consumed together with food, may provide additional nutrients and improve the sensory properties. The interest in edible packaging is increasing due to the environmental protection[22].

Food packaging uses different materials based films (e.g. Starch/clay nanocomposite films) by uniformly dispersing the nanoparticles in montmorillonite in a variety of materials based on starch using polymer processing techniques[23]. Starch (a semi-crystalline polymer) plays an indispensable role in human and animal diets and is stored in granules as one of the reserve in plants[24]. Starch is composed of amylase and amylopectin with repeating 1, 4-a-D glucopyranosyl unit. Amylase is almost linear and the repeated units are bonded, while amylopectin has a (1-4) linked backbone[25] [26]. The study was carried out to systematically investigate and verify the interactions of polymer film in samples of vegetables (lettuce and spinach)[27]. The resulting films were tested and analysed by polarized light microscopy as well as scanning electron microscopy analysis and the degree of dispersion of the components 
in the starch matrix. The polymer nanocomposite films were prepared by uniformly dispersing functionalized phyllosilicates using the thermoplastic processing techniques consisting of starch polymer melt. Furthermore, these nanocomposite films were also prepared using other polymer matrices of pure starch, and potato starch mixture of biodegradable polyester. It is important to study the interaction between the material food packaging and food. The plastic materials themselves are not inert, because the direct contact between the plastic container and packaged products can cause migration of the food product. It has been reported that "the amount of any component that migrates to food depends on the initial concentration of the specific component of the polymer, its solubility, and the temperature, mechanical stresses and contact time"[27].

\subsection{Edible Films and Coatings}

Different types of edible films as well as coatings can be manufactured and developed from a number of materials characterized by moldability[28]. During the production of film, the materials to be dispersed are generally dissolved in a suitable solvent such as water/ alcohol /a mixture of both. During this process, antimicrobial agents, colorants or flavouring agents may be added depending upon the requirement. The solution is then cast into a film and subjected to drying under suitable temperature and relative humidity conditions. In the solutions using food, films may be applied by numerous methods for example brushing, drying, dipping, and spraying. Edible films can be generally divided into three different categories: lipids (fatty acids, waxes, acyl glycerol), hydrocolloids (proteins, polysaccharides and alginate), and composites. Polysaccharides family that includes cellulose, chitosan, starch derivatives, pectin derivatives, seaweed extracts, and microbial fermentation gums is generally used to make edible coatings[29-31]. Polysaccharide coatings act as the agents delaying moisture loss from the food products[32].

\subsection{Cellulose and its Derivatives}

Cellulose is one of the most important biopolymers that consists of repeating units of Dglucose linked through $\beta-1,4$ glyosidic bonds[4, 33-36]. It consists of tight packing of the cellulosic polymer chains along with the crystalline structure that resist dissolution in aqueous media[37]. The only way to increase the water solubility is the treatment of cellulose with alkali to swell the structure and react it with methyl chloride, chloroacetic acid, and propylene oxide to produce carboxymethyl cellulose, methylcellulose, hydroxypropylmethylcellulose and hydroxypropylcellulose[38-40]. All of these materials make a good film, and generally have 
no taste and aroma while remaining moderately flexible, transparent, and resistant to oils and fats[41, 42].

\subsection{Chitin and Chitosan}

Chitin is a naturally occurring biorenewable polymer[43]. It is found in various biological materials such as the shellfish exoskeleton and fungal cell walls. Structurally, it resembles a cellulose. The difference is that the acetamide group replaces the secondary hydroxyl group of the second carbon atom in the hexose repeat unit is[44]. Chitin is deacetylated in the presence of a base and chitosan is formed. It is a copolymer and is composed of units ( $\beta$ (1-4)-2acetamido-D-glucose and ( $\beta$ (1-4)-2-acetamide-D-glucose.) Chitosan is characterized by antimicrobial activity and is used as a coating on fruit and vegetable products such as cucumbers, strawberries, peppers to form an antibacterial layer [44].

\subsection{Starch}

An example of a polymeric hydrocarbon is starch made up of anhydroglucose units. Starch is primarily composed of two types of glucose polymers: linear amylase and branched amylopectin[45]. It is used to form biodegradable starch coatings. Such production is characterized by low cost and good mechanical properties[46]. Corn starch is also a good source for creating films. It consists of $25 \%$ amylase and $75 \%$ amylopectin. Starch is a very promising material that occurs in many plants. It is completely degradable in soil and water. It supports the process of biodegradation of biodegradable mixed plastics. Starch has been treated in an extruder by the use of mechanical thermal energy to be converted into the thermoplastic material[47]. In the manufacturing of thermoplastic starch plasticizers, it reduces the hydrogen bonds within the molecular level in order to ensure the stability of properties of the product. In the case of food, due to the hygroscopic nature of the absorbent, starch material may serve as absorbers for meat exudate[48].

\subsection{Lipid compounds}

The protective coating of the lipid compounds consists of acetylated monoglycerides, waxes, and natural surfactants. The paraffin wax and beeswax are most effective. Their function is primarily blocking the moisture transport due to the low polarity of paraffin distillate fractions derived from petroleum, which consists of a mixture of hydrocarbons obtained by polymerization of ethylene[49]. Acetylated monoglycerides coatings have been used in industries (e.g. poultry and meat) as moisture retardants during storage[50]. Shellac resins 
secreted by Laccifer Lacca insects consisting of a complex mixture of aliphatic, acyclic hydroxy acid polymers are also used for packaging applications. This resin is soluble in the alcohols and in basic alkaline solutions. Shellac resin can be applied as an indirect food additive to coatings. It is mainly used in the pharmaceutical industry. Typically, the resins are used to coat the citrus fruit. They are in this case designed to give a high gloss, and create additional gas-permeable barriers. Since coatings have different permeability and the ability to block the gas through the holes in the skin affects the exchange of various gases[51].

\subsection{Proteins}

Proteins mainly occur as fibrous proteins, or protein clusters. Protein fibers are closely linked by hydrogen bonding[52]. The protein complex is spherical structure linked by a covalent bond (disulphide), hydrogen, which is both ionic and hydrophobic. Solutions of the protein in the form of a solvent, which is water, ethanol or a mixture of water and ethanol form protein films[50]. The protein must be denatured to create complex structures required for film formation[31]. An example of a protein coating is gelatin[53]. It is used for encapsulation of food, pharmaceutical and oil phases. This encapsulation protects against oxygen and light, and also reduces the dose. In the case of zein, i.e. protein maize, it is necessary to add a plasticizer to increase the flexibility. Similarly, in the case of the wheat gluten, the addition of a plasticizer, i.e. glycerol, is necessary to increase the flexibility of the film. Gluten strength of the film can be increased by the addition of glutaraldehyde.

\section{Biodegradable Film-forming Materials}

In 2011, the global production of plastics was amounted to approximately 280 million tons. Large use of plastics for food strongly affects the environment. For this reason, the packaging industry strives to develop biodegradable packaging materials. Most biodegradable polyesters have a high potential for use in packaging because they have thermoplastic properties, high modulus and good processing properties [54]. Biodegradable polyesters can be divided into aliphatic and aromatic groups and the source of each group can be distinguished as renewable and non-renewable. Polylactic acid is an aliphatic polyester derived from renewable sources: starch and sugar[55, 56]. High rigidity and transparency of polylactic acid make it a suitable material for the production of plastic bottles, rigid trays and cups. The main purpose of food packaging is the protection of foods against oxidation and microbiological spoilage. It creates active food packaging, which can enhance the protection by adding active substances: 
antibacterial and anti-oxidants. The addition of antioxidants in the packaging material provides advantages over the direct addition of food, reducing the amount of active ingredient introduced directly into the food product. The activity is primarily concentrated on the surface. The process is characterized by a controlled release of suitable food substance from a matrix[57]. However, there is a growing consumer demand for food without the addition of artificial substances. There has also been an augmented demand for the use of natural antioxidants present in, inter alia, acerola pulp, oregano, rosemary, and their use in packaging materials[58] [59].

Studies have shown that tocopherol added to the film-forming material for food containers during production has a low loss. The extruded films at a temperature $\left(216-220{ }^{\circ} \mathrm{C}\right)$ exhibited a loss of $18 \%$. Ecoflex films with the addition of polylactic acid showed some reduction in tocopherol content of about $16 \%$, even though the extrusion temperatures were not different from those used for film Ecoflex extrusion, which were in the range of $\left(138-170{ }^{\circ} \mathrm{C}\right)[60]$. Other studies have suggested tocopherol losses by about $15 \%$ during extrusion with the addition of Polylactic acid at a temperature $\left(165-170{ }^{\circ} \mathrm{C}\right)[59]$. The differences in the content of tocopherol, may result from a stronger interaction with tocopherol Polylactic acid[60]. The extract from the leaves of olive oil was used to create film, which was rich in oleuropein (20.8\%). After creating a shell, the content of oleuropein in the film was rated. The best results were obtained using a double extraction procedure. The data obtained from the chromatogram of the extract showed two major peaks which have been identified as oleuropein and oleuroside. Both compounds show a very similar structure which differ only in the shift of the double bond in the exocyclic side-chain of the ring. The thermal stability of oleuropein was also examined[60]. No significant loss of substance was observed overnight when an extract of olive leaf was treated at $100{ }^{\circ} \mathrm{C}$. When it was incubated at $165^{\circ} \mathrm{C}$ for 1 hour, the loss was $75 \%$. The in vitro tests suggest that the high temperature during extrusion may affect the stability of oleuropein. Moreover, the influence of factors such as the interaction of the monomer with the plastic, the increase in pressure and the presence of additives may also influence both the stability and balance of these compounds. Oleuropein and oleuroside have the same catechol moiety and similar antioxidant capacity $[60,61]$. This may suggest that the increase in oleuroside would prevent the loss of antioxidant capacity derived from the reduction of oleuropein resulting from film processing. Antioxidant films showed a high content of active radicals 2,2-diphenyl-1picrylhydrazyl, which are used to measure the antioxidant capacity of the films [60].

\section{Nanocomposite Packaging Materials}

Selected, nanoparticles often function as an anti-microbial and reinforcing materials, when they are added to the polymers[45, 62]. So far in the field of packaging materials, industry has 
focused on layered clays and silicates, due to their availability, low cost and simplicity of adaptation. The interaction between silicates and polymer chains leads to perfect types of nanocomposites. Intercalated nanocomposites are the result of diffusion of the polymer chains in the layers of the clay. This results in a multilayer structure composed alternately of polymer layers and inorganic layers within a few nanometers. The layers of polymer and clay randomly dispersed in the matrix are taken up by exfoliated nanocomposites[45]. Exfoliated polymer nanocomposites include extensive penetration of polymer and clay layer to be randomly dispersed in the matrix [63]. The interaction between the polymer matrix and clay was found to shows the best properties of exfoliated nanocomposites [64]. Figure 2 (a-c) shows the AFM scan of the constrained polymer region in. It was concluded from the study that "the constrained region of semicrystalline polymers will not significantly affect permeability unless the overall crystallinity is decreased. The main effect of the constrained region is to lower free volume. That will not be significant in crystalline region" [64].

Clay layer forms a barrier to gas and water resulting in a complicated path within the film. The incorporation of nanoclay into a bio-polymer structures significantly improved the barrier, properties overcoming the main limitations of biopolymer films [63]. Clays were also tested in order to improve the mechanical strength of biopolymers. Adding clay nanocomposites reduces the permeability of water vapor. The optimum concentration of nanoclay and a plasticizer to form a film-forming starch gel greatly improves the mechanical properties[63]. Cellulose is a strong and a natural polymer. Nanofibers of cellulosic material are widely available and inexpensive. They are environmentally friendly, easily recycled by combustion and require low power consumption in production[65]. Basically, there are two types of nanoreinforcements, which can be obtained from cellulose, i.e. microfibrils and whiskers[4]. The basic method of obtaining cellulose whiskers is acidic hydrolysis, which involves removing amorphous regions of the filaments, leaving crystalline regions intact. "Microcrystalline cellulose is formed by particles of hydrolysed cellulose consisting of a very large number of microcrystals of cellulose amorphous area"[6]. There are studies showing that the surface modification of the fibers through different chemical treatment results in an improved adhesion between the fibers and matrix. The cellulose fibers are modified by acylation with a fatty acid to prepare them for the polyethylene composite. The modification ensures increased mechanical and thermal stability as well as the reduced uptake of water in the material. The addition of the surfactant can improve the compatibility between the cellulose and the hydrophobic matrix. The hydrophilic group of surfactant absorbed on the surface of the cellulose and the hydrophobic tail anchors the matrix, avoiding the aggregation of cellulose fillers. Improved nanocomposite performance has been 
found to result from the better adhesion and wettability between the phases as well as a uniform distribution of the reinforcing materials in the matrix[6].

It has also been observed that the silica nanoparticles in a polymer matrix significantly improve the mechanical properties. Adding silica nanoparticles to the polypropylene improves the tensile properties of the material for an enhanced elongation. Modulus of elasticity increases along with the improvement in the material stiffness and the oxygen barrier. The nanocomposite of polyvinyl alcohol with silica nanoparticles are also produced by radical copolymerization of vinyl acetate and vinyl silica nanoparticles. Such nanocomposites were found to improve the thermal and mechanical properties in comparison to the pure nanocomposite of polyvinyl alcohol because of the strong interaction between silica nanoparticles and the matrix polymer by a covalent bond [66, 67]. The use of conventional chemical synthesis routes for the production of polymers has a main route for their preparation especially bio-polyesters. Among them, lactic acid has the potential to be used as a renewable packaging material. Polylactic acid monomers can be easily produced by the carbohydrate fermentation. The raw carbohydrate materials may include agricultural products such as corn, wheat, molasses, whey etc. The properties of polylactic acid are slightly different in the two forms (L or D), of the monomer of lactic acid. Monomer L generally exhibits a high melting point and high crystallinity. In contrast, a mixture of monomer D and L results in amorphous polymer with a low glass transition temperature[56]. Polyhydroxybutyrate is collected by a number of bacteria as a reserve energy and carbon rich source with biodegradability and biocompatibility that can be used in the industry[68]. Polyhydroxybutyrate is a highly crystalline thermoplastic polymer material with low permeability to water vapor and is similar to low density polyethylene (LDPE)[69]. Lactic acid and polyhydroxybutyrate offer numerous opportunities for the use in food packaging. They can be formed as a foil or used for the preparation of molded objects. They can be used with dairy products, beverages, fresh meat products and prepared dishes [56]. The glass transition temperature was found to increase with the incorporation of clay content and was attributed to the microstructure of the composite. Layered silicate nanocomposites from lactic acid prepared by simple extrusion of the alloy were found to cause the improvement of material properties in the solid and melted state, compared to the matrix without clay[56].

Polycaprolactone is a linear polyester produced by the ring opening polymerization of $\varepsilon$ caprolactone[70]. This is a semi-crystalline polymer with a high degree of crystallinity (about $50 \%$ ). It shows a high elongation at break and low modulus along with its physical properties making it a commercially-available very attractive material for commodity applications. It is 
an interesting material for medical and agricultural applications[70]. Due to the low melting temperature, it must be blended with other types of polymers/ materials to get the desired properties[55, 71]. Different compositions of polycaprolactone nanocomposites were prepared and layered silicate caprolactone was modified by melting, mixing or catalyzed ring-opening polymerization of caprolactone. Micro-composites were prepared by the direct melting and mixing the pristine polycaprolactone and montmorillonite. Exfoliated polymer nanocomposites materials were obtained by polymerization of caprolactone (through ring-opening polymerisation) and modified with layered silicate, using dibutyltin dimethoxide as an initiator of the catalytic process. It has been found that the water sorption increases with the increasing content of montmorillonite, in particular for micro-composites containing unmodified montmorillonite[72]. In exfoliated nanocomposites filled with sheet silicates, characterized by a high aspect ratio, the mechanical properties such as impact resistance, Young's modulus, flexural modulus and bending temperature prior to charging tend to be increased. This suggests that these materials can replace a conventional matrix in applications requiring mechanical resistance. Bio-packaging should be easily biodegradable after a specified period of time. The introduction of inorganic particles in a biopolymer matrix is suitable for improving the physical properties of the original polymer, but also suitable for increasing their rate of biodegradation. The biodegradability of the nanocomposites generally depends on the nature of pristine layered silicate and surfactants used to modify layer silicates. It is therefore possible to control the biodegradation by choosing several biopolymers with organically modified layered silicate. Consequently, these systems are rapidly emerging as the most promising in the active packaging for food [72].

\section{Biodegradability of Polymers}

\subsection{The Use of Bioplastics}

During the last few decades, mankind has observed a significant increase in the use of synthetic plastics (e.g. polyvinylchloride, polystyrene, polyethylene terephthalate, polyethylene, polypropylene, polyamide etc). These synthetic polymers are available at a low price, have good mechanical properties such as tensile strength, tear strength, good oxygen barrier and carbon dioxide. However, the rising environmental concerns demand restriction in their extensive use especially because they are not biodegradable and not fully capable of being recycled. On the other hand, in the case of biopolymers, compost-ability is an important attribute, allowing disposal of packaging in the soil. According to the European bioplastics, biopolymers must be biodegradable, especially in terms of composting so that they can act as 
fertilizers and soil conditioners. However, some bioplastics based on natural monomers may lose biodegradability through chemical modification of the polymerization. A lot of bioplastics contain a mixture of ingredients such as synthetic polymers along with the additives to enhance the functional characteristics of the final products in order to extend the scope of application. When both the additives and pigments are based on renewable energy sources, it is possible to obtain a polymer with about $100 \%$ by weight of biodegradable compounds[8]. It is also important to examine the changes that may occur during the interaction of bioplastics with food.

\subsection{Biodegradation of Bioplastics}

Generally, the biodegradable polymers are classified based on the source of their origin[73]:

- Polymers made from biomass (polysaccharides, proteins, polypeptides, polynucleotides).

- Chemically synthesized products from renewable monomers or derived from natural sources of biomass and oil (lactic acid or bio-polyester).

- Polymers produced by the activity of microorganisms, including genetically modified bacteria (curdian, xanthan, polyhydroxybutyrate, bacterial cellulose, pullulan).

Although natural polymers are getting greater attention these days, there are several problems associated with them such as efficiency, processing and costs. In particular, brittleness and high water vapor and gas permeability, poor resistance to prolonged processing operation causes limitations in their use. The use of nanotechnology for these polymers may open new opportunities to improve their properties and characteristics such as cost, performance. Nanocomposites may exhibit a significant improvement in thermal, mechanical, and physicochemical barrier, as compared to the pristine polymers. In particular, clay based nanocomposites provide excellent barrier properties due to the presence of the clay layer which delays the pathway molecules making a more complex process. Bioplastics should imitate the life cycle of biomass, which includes protection of fossil resources, water and carbon dioxide production. The rate of biodegradation is dependent on temperature, humidity, quantity and type of microorganisms. When all these conditions are present, the rapid degradation process occurs. In industrial composting process, most of the bioplastics are converted to biomass, water and carbon dioxide in approximately 6 to 12 weeks[8].

Polymer products have to biodegrade in a controlled way: natural polymers such as rubber, humus, lignin, and synthetic polymers (e.g. polyolefins) must follow the mechanism 
of oxo-biodegradation[74]. During the degradation of the oxocarboxylic acid molecules, aldehydes, ketones and alcohols with low molecular mass are produced by peroxidation process which is initiated by heat or light, which are the main cause of the loss of mechanical properties of the carbohydrate polymers. Then, bacteria, fungi, enzymes begin bioassimilation increasing biomass and $\mathrm{CO}_{2}$, which forms cavities. Generally antioxidants and stabilizers are added to the synthetic polymers to protect the polymer from oxidation during the mechanical processing and ensure the required shelf-life. On the one hand, the use of antioxidants is essential to improve the performance of the materials but on the other hand, in the event of biodegradability, it is better not to add antioxidants during the processing of the polymer[8]. Hydro-biodegradation is a process that yields bio- assimilable products from cellulose, starch and polyesters. The aliphatic polyester is hydrolysed and bio-assimilated rapidly in an aqueous medium[75]. Natural products such as cellulose starch are swellable and wetted with water and therefore biodegradable. They are not useful for packaging food technology, which is required for water resistance. Between these two extremes, there are hydro-biodegradable aliphatic polyesters namely polylactic acid as well as poly (hydroxyacid). The product must be defined as composting biodegradable and it must disintegrate in a short time. The composting product must be compatible with the composting process, it means that it should not release toxic substances and not change the quality of the compost produced[75]. Products that are kept in containers may have poor properties and a strong acidity. It is therefore necessary to evaluate the effectiveness and suitability of biopolymers in solutions for storage and food. Absorption and interaction between the chemicals and polymer may affect the properties (e.g. mechanical) of the polymer being investigated. The flexibility of the sample is tested by measuring the stress, tensile elongation at break, while chemical resistance is checked by immersion in strong and weak acids as a function of time, simulating the actual conditions at ambient temperature $\left(23^{\circ} \mathrm{C}\right)$ at $18{ }^{\circ} \mathrm{C}, 23{ }^{\circ} \mathrm{C}$ and $29^{\circ} \mathrm{C}$. A solution of a weak acid is produced from acetic acid and the strong acid solution is prepared with hydrochloric acid [76].

\subsection{Utilization of Bioplastics}

Biodegradable materials are suitable for composting processes or the wastewater system and open up new opportunities for waste disposal. In general, we distinguish two ways of biopolymer utilization: terrestrial and aquatic. Among the terrestrial ways, we distinguish the soil and compost utilization. On the other hand, aquatic ways include: aerobic sewage sludge, and anaerobic sewage sludge [77]. In the case of anaerobic biodegradation terrestrial, we distinguish landfill. The scheme is as follows: 
1) Aerobic biodegradation of bioplastics (such as composting):

$$
\text { Polymer }+\mathrm{O}_{2} \rightarrow \mathrm{CO}_{2}+\mathrm{H}_{2} \mathrm{O}
$$

2) Anaerobic biodegradation of bioplastics (such as anaerobic digestion and landfill):

$$
\text { Polymer } \rightarrow \mathrm{CO}_{2}+\mathrm{CH}_{4}+\mathrm{H}_{2} \mathrm{O}
$$

The waste from the original plastic packaging constitute a large group and the volume and the amount of recovered material is low. The topic is still the subject of discussion on biodegradable packaging. There are several technologies designed for the treatment of plastic packaging waste:

- Incineration with energy recovery.

- The release of plastic with a high calorific value of household waste for selective combustion.

- Selective collection of waste plastics, sorting, cleaning and mechanical recycling.

Recently, because of the people's desire to use biodegradable materials, the industry has striven to create better bags and products, although the process is more expensive. However, they are recommended for home system and commercial composting[78].

\section{Conclusions}

One of the biggest barriers in the recycling of conventional waste plastics is the absence of a stable and reliable supply of quality sorted materials. It specifies the practical difficulties in the recycling of spent plastics: difficulties in separating and identifying plastics, limited recycling technologies, degradation after repeated processing, polymer lower mass density, high time-consumption and cost. Biodegradable plastics generally decompose into naturally occurring components such as water, carbon dioxide and biomass, and they are not retained in the environment for many years. This decomposition undergoes the same processes as organic matter. Thus, biodegradable plastics can be disposed of together with organic waste. Moreover, some biodegradable plastics can be a component of renewable energy sources. Through the widespread use of biodegradable materials, we could reduce the amount of waste, lower the greenhouse gas emissions and ensure the sustainable use of environmental resources. 


\section{References}

1. Singh S, Sharma S, Umar A, et al (2018) Recycling of Waste Poly(ethylene terephthalate) Bottles by Alkaline Hydrolysis and Recovery of Pure Nanospindle-Shaped Terephthalic Acid. J Nanosci Nanotechnol 18:5804-5809 . doi: 10.1166/jnn.2018.15363

2. Sharuddin SDA, Abnisa F, Daud WMAW, Aroua MK (2016) A review on pyrolysis of plastic wastes. Energy Convers Manag 115:308-326 . doi: 10.1016/j.enconman.2016.02.037

3. Rodriguez-Perez S, Serrano A, Pantion AA, Alonso-Farinas B (2018) Challenges of scaling-up PHA production from waste streams. A review. J Environ Manage 205:215230 . doi: 10.1016/j.jenvman.2017.09.083

4. Trache D, Hazwan Hussin M, Mohamad Haafiz MK, Kumar Thakur V (2017) Recent progress in cellulose nanocrystals: sources and production. Nanoscale 9:1763-1786 . doi: 10.1039/C6NR09494E

5. Singha AS, Thakur VK (2008) Fabrication of Hibiscus sabdariffa fibre reinforced polymer composites. Iran Polym J 17:541-553

6. Attaran SA, Hassan A, Wahit MU (2017) Materials for food packaging applications based on bio-based polymer nanocomposites: A review. J Thermoplast Compos Mater 30:143173 . doi: $10.1177 / 0892705715588801$

7. Kumar N, Kaur P, Bhatia S (2017) Advances in bio-nanocomposite materials for food packaging: a review. Nutr Food Sci 47:591-606 . doi: 10.1108/NFS-11-2016-0176

8. Siracusa V, Rocculi P, Romani S, Dalla Rosa M (2008) Biodegradable polymers for food packaging: a review. Trends Food Sci Technol 19:634-643 . doi: 10.1016/j.tifs.2008.07.003

9. Song F, Tang D-L, Wang X-L, Wang Y-Z (2011) Biodegradable Soy Protein IsolateBased Materials: A Review. Biomacromolecules 12:3369-3380 . doi: $10.1021 / \mathrm{bm} 200904 \mathrm{x}$

10. Li J, Li R, Li J (2017) Current research scenario for microcystins biodegradation - A review on fundamental knowledge, application prospects and challenges. Sci Total Environ 595:615-632 . doi: 10.1016/j.scitotenv.2017.03.285

11. Leja K, Lewandowicz G (2010) Polymer Biodegradation and Biodegradable Polymers - a Review. Pol J Environ Stud 19:255-266

12. Shah AA, Hasan F, Shah Z, et al (2013) Biodegradation of natural and synthetic rubbers: A review. Int Biodeterior Biodegrad 83:145-157 . doi: 10.1016/j.ibiod.2013.05.004

13. Rhim J-W, Park H-M, Ha C-S (2013) Bio-nanocomposites for food packaging applications. Prog Polym Sci 38:1629-1652 . doi: 10.1016/j.progpolymsci.2013.05.008 
14. Singh S, Gaikwad KK, Lee M, Lee YS (2018) Temperature-regulating materials for advanced food packaging applications: a review. J Food Meas Charact 12:588-601 . doi: 10.1007/s11694-017-9672-5

15. Thakur VK, Kessler MR (2014) Synthesis and characterization of AN-g-SOY for sustainable polymer composites. ACS Sustain Chem Eng 2:2454-2460

16. Adu C, Jolly M, Thakur VK(2018) Exploring new horizons for paper recycling: A review of biomaterials and biorefinery feedstocks derived from wastepaper. Curr Opin Green Sustain Chem. doi: 10.1016/j.cogsc.2018.03.003

17. Jayanth D, Kumar PS, Nayak GC, et al (2018) A Review on Biodegradable Polymeric Materials Striving Towards the Attainment of Green Environment. J Polym Environ 26:838-865 . doi: 10.1007/s10924-017-0985-6

18. Pappu A, Patil V, Jain S, et al (2015) Advances in industrial prospective of cellulosic macromolecules enriched banana biofibre resources: A review. Int J Biol Macromol 79:449-458 . doi: 10.1016/j.ijbiomac.2015.05.013

19. Aziz M, Karboune S (2018) Natural antimicrobial/antioxidant agents in meat and poultry products as well as fruits and vegetables: A review. Crit Rev Food Sci Nutr 58:486-511 . doi: $10.1080 / 10408398.2016 .1194256$

20. Tawakkal ISMA, Cran MJ, Miltz J, Bigger SW (2014) A Review of Poly(Lactic Acid)Based Materials for Antimicrobial Packaging. J Food Sci 79:R1477-R1490 . doi: $10.1111 / 1750-3841.12534$

21. Johansson C, Bras J, Mondragon I, et al (2012) Renewable Fibers and Bio-Based Materials for Packaging Applications - a Review of Recent Developments. Bioresources 7:25062552

22. Otoni CG, Avena-Bustillos RJ, Azeredo HMC, et al (2017) Recent Advances on Edible Films Based on Fruits and Vegetables-A Review. Compr Rev Food Sci Food Saf 16:11511169 . doi: $10.1111 / 1541-4337.12281$

23. Othman SH (2014) Bio-nanocomposite Materials for Food Packaging Applications: Types of Biopolymer and Nano-sized Filler. In: Chin NL, Man HC, Talib RA (eds) 2nd International Conference on Agricultural and Food Engineering (cafe 2014) - New Trends Forward. Elsevier Science Bv, Amsterdam, pp 296-303

24. Miculescu F, Maidaniuc A, Voicu SI, et al (2017) Progress in Hydroxyapatite-Starch Based Sustainable Biomaterials for Biomedical Bone Substitution Applications. ACS Sustain Chem Eng 5:8491-8512 . doi: 10.1021/acssuschemeng.7b02314

25. Lambert J-F, Poncelet G (1997) Acidity in pillared clays: origin and catalytic manifestations. Top Catal 4:43-56 . doi: 10.1023/A:1019175803068

26. Petersen K, Væggemose Nielsen P, Bertelsen G, et al (1999) Potential of biobased materials for food packaging. Trends Food Sci Technol 10:52-68 . doi: 10.1016/S09242244(99)00019-9 
27. Avella M, De Vlieger JJ, Errico ME, et al (2005) Biodegradable starch/clay nanocomposite films for food packaging applications. Food Chem 93:467-474 . doi: 10.1016/j.foodchem.2004.10.024

28. Yousuf B, Qadri OS, Srivastava AK (2018) Recent developments in shelf-life extension of fresh-cut fruits and vegetables by application of different edible coatings: A review. Lwt-Food Sci Technol 89:198-209 . doi: 10.1016/j.lwt.2017.10.051

29. Cazon P, Velazquez G, Ramirez JA, Vazquez M (2017) Polysaccharide-based films and coatings for food packaging: A review. Food Hydrocoll 68:136-148 . doi: 10.1016/j.foodhyd.2016.09.009

30. Thakur VK, Thakur MK (2014) Recent Advances in Graft Copolymerization and Applications of Chitosan: A Review. ACS Sustain Chem Eng 2:2637-2652 . doi: $10.1021 / \mathrm{sc} 500634 \mathrm{p}$

31. Thakur MK, Thakur VK, Gupta RK, Pappu A (2016) Synthesis and Applications of Biodegradable Soy Based Graft Copolymers: A Review. ACS Sustain Chem Eng 4:1-17 . doi: 10.1021/acssuschemeng.5b01327

32. Azeredo HMC, Waldron KW (2016) Crosslinking in polysaccharide and protein films and coatings for food contact - A review. Trends Food Sci Technol 52:109-122 . doi: 10.1016/j.tifs.2016.04.008

33. Singha AS, Thakur VK (2008) Saccaharum Cilliare Fiber Reinforced Polymer Composites. E-J Chem 5:782-791 . doi: 10.1155/2008/941627

34. Thakur VK, Singha AS, Thakur MK (2012) Biopolymers Based Green Composites: Mechanical, Thermal and Physico-chemical Characterization. J Polym Environ 20:412421 . doi: 10.1007/s10924-011-0389-y

35. Thakur VK, Singha AS (2010) Mechanical and Water Absorption Properties of Natural Fibers/Polymer Biocomposites. Polym-Plast Technol Eng 49:694-700 . doi: $10.1080 / 03602551003682067$

36. Singha AS, Thakur VK (2009) Fabrication and Characterization of H. sabdariffa FiberReinforced Green Polymer Composites. Polym-Plast Technol Eng 48:482-487 . doi: $10.1080 / 03602550902725498$

37. Singha AS, Thakur VK (2010) Synthesis, Characterization and Study of Pine Needles Reinforced Polymer Matrix Based Composites. J Reinf Plast Compos 29:700-709 . doi: $10.1177 / 0731684408100354$

38. Sadeghi-Varkani A, Emam-Djomeh Z, Askari G (2018) Physicochemical and microstructural properties of a novel edible film synthesized from Balangu seed mucilage. Int J Biol Macromol 108:1110-1119 . doi: 10.1016/j.ijbiomac.2017.11.029

39. Dehghani S, Hosseini SV, Regenstein JM (2018) Edible films and coatings in seafood preservation: A review. Food Chem 240:505-513 . doi: 10.1016/j.foodchem.2017.07.034

40. Singha AS, Thakur VK (2010) Synthesis and Characterization of Short Grewia optiva Fiber-Based Polymer Composites. Polym Compos 31:459-470 . doi: 10.1002/pc.20825 
41. Shah U, Naqash F, Gani A, Masoodi FA (2016) Art and Science behind Modified Starch Edible Films and Coatings: A Review. Compr Rev Food Sci Food Saf 15:568-580 . doi: $10.1111 / 1541-4337.12197$

42. Kerch G (2015) Chitosan films and coatings prevent losses of fresh fruit nutritional quality: A review. Trends Food Sci Technol 46:159-166 . doi: 10.1016/j.tifs.2015.10.010

43. Thakur VK, Voicu SI (2016) Recent advances in cellulose and chitosan based membranes for water purification: a concise review. Carbohydr Polym 146:148-165

44. Elsabee MZ, Abdou ES (2013) Chitosan based edible films and coatings: A review. Mater Sci Eng C-Mater Biol Appl 33:1819-1841 . doi: 10.1016/j.msec.2013.01.010

45. Madhumitha G, Fowsiya J, Roopan SM, Thakur VK (2018) Recent advances in starchclay nanocomposites. Int J Polym Anal Charact 0:null . doi: 10.1080/1023666X.2018.1447260

46. Xu YX, Kim KM, Hanna MA, Nag D (2005) Chitosan-starch composite film: preparation and characterization. Ind Crops Prod 21:185-192 . doi: 10.1016/j.indcrop.2004.03.002

47. Mitrus M, Combrzyński M, Kupryaniuk K, et al (2016) A STUDY OF THE SOLUBILITY OF BIODEGRADABLE FOAMS OF THERMOPLASTIC STARCH. J Ecol Eng 17:184-189 . doi: 10.12911/22998993/64554

48. Umaraw P, Verma AK (2017) Comprehensive review on application of edible film on meat and meat products: An eco-friendly approach. Crit Rev Food Sci Nutr 57:12701279 . doi: $10.1080 / 10408398.2014 .986563$

49. Phan D, Debeaufort F, Peroval C, et al (2002) Arabinoxylan-lipid-based edible films and coatings. 3. Influence of drying temperature on film structure and functional properties. $\mathrm{J}$ Agric Food Chem 50:2423-2428 . doi: 10.1021/jf010898r

50. Kester J, Fennema O (1986) Edible Films and Coatings - a Review. Food Technol 40:4759

51. Hagenmaier R, Baker R (1993) Reduction in Gas-Exchange of Citrus-Fruit by Wax Coatings. J Agric Food Chem 41:283-287 . doi: 10.1021/jf00026a029

52. Thakur VK, Thunga M, Madbouly SA, Kessler MR (2014) PMMA-g-SOY as a sustainable novel dielectric material. RSC Adv 4:18240-18249 . doi: 10.1039/C4RA01894J

53. Thakur S, Govender PP, Mamo MA, et al Recent progress in gelatin hydrogel nanocomposites for water purification and beyond. Vacuum. doi: 10.1016/j.vacuum.2017.05.032

54. Rhim J-W (2007) Mechanical and water barrier properties of biopolyester films prepared by thermo-compression. Food Sci Biotechnol 16:62-66

55. Lim L-T, Auras R, Rubino M (2008) Processing technologies for poly(lactic acid). Prog Polym Sci 33:820-852 . doi: 10.1016/j.progpolymsci.2008.05.004 
56. Dubey SP, Thakur VK, Krishnaswamy S, et al (2017) Progress in environmental-friendly polymer nanocomposite material from PLA: Synthesis, processing and applications. Vacuum 146:655-663 . doi: 10.1016/j.vacuum.2017.07.009

57. Bolumar T, Andersen ML, Orlien V (2011) Antioxidant active packaging for chicken meat processed by high pressure treatment. Food Chem 129:1406-1412 . doi: 10.1016/j.foodchem.2011.05.082

58. Camo J, Lorés A, Djenane D, et al (2011) Display life of beef packaged with an antioxidant active film as a function of the concentration of oregano extract. Meat Sci 88:174-178 . doi: 10.1016/j.meatsci.2010.12.019

59. Manzanarez-López F, Soto-Valdez H, Auras R, Peralta E (2011) Release of $\alpha$-Tocopherol from Poly(lactic acid) films, and its effect on the oxidative stability of soybean oil. J Food Eng 104:508-517 . doi: 10.1016/j.jfoodeng.2010.12.029

60. Marcos B, Sárraga C, Castellari M, et al (2014) Development of biodegradable films with antioxidant properties based on polyesters containing $\alpha$-tocopherol and olive leaf extract for food packaging applications. Food Packag Shelf Life 1:140-150 . doi: 10.1016/j.fps1.2014.04.002

61. Laguerre M, Giraldo LJL, Piombo G, et al (2009) Characterization of Olive-Leaf Phenolics by ESI-MS and Evaluation of their Antioxidant Capacities by the CAT Assay. J Am Oil Chem Soc 86:1215-1225 . doi: 10.1007/s11746-009-1452-x

62. Miculescu M, Thakur VK, Miculescu F, Voicu SI (2016) Graphene-based polymer nanocomposite membranes: a review. Polym Adv Technol 27:844-859 . doi: $10.1002 /$ pat.3751

63. Ludueña LN, Alvarez VA, Vazquez A (2007) Processing and microstructure of PCL/clay nanocomposites. Mater Sci Eng A 460-461:121-129 . doi: 10.1016/j.msea.2007.01.104

64. Adame D, Beall GW (2009) Direct measurement of the constrained polymer region in polyamide/clay nanocomposites and the implications for gas diffusion. Appl Clay Sci 42:545-552 . doi: 10.1016/j.clay.2008.03.005

65. Paul Podsiadlo $\dagger$, Seok-Youl Choi \$, Bongsup Shim $\uparrow$, et al (2005) Molecularly Engineered Nanocomposites: Layer-by-Layer Assembly of Cellulose Nanocrystals. http://pubs.acs.org/doi/abs/10.1021/bm050333u. Accessed 14 Mar 2018

66. Jia X, Li Y, Cheng Q, et al (2007) Preparation and properties of poly(vinyl alcohol)/silica nanocomposites derived from copolymerization of vinyl silica nanoparticles and vinyl acetate. Eur Polym J 43:1123-1131 . doi: 10.1016/j.eurpolymj.2007.01.019

67. Tang S, Zou P, Xiong H, Tang H (2008) Effect of nano-SiO2 on the performance of starch/polyvinyl alcohol blend films. Carbohydr Polym 72:521-526 . doi: 10.1016/j.carbpol.2007.09.019

68. van der Walle GAM, Buisman GJH, Weusthuis RA, Eggink G (1999) Development of environmentally friendly coatings and paints using medium-chain-length poly(3hydroxyalkanoates) as the polymer binder. Int J Biol Macromol 25:123-128 . doi: 10.1016/S0141-8130(99)00025-2 
69. Bugnicourt E, Cinelli P, Lazzeri A, Alvarez V (2014) Polyhydroxyalkanoate (PHA): Review of synthesis, characteristics, processing and potential applications in packaging. Express Polym Lett 8:791-808 . doi: 10.3144/expresspolymlett.2014.82

70. Hajiali F, Tajbakhsh S, Shojaei A (2018) Fabrication and Properties of Polycaprolactone Composites Containing Calcium Phosphate-Based Ceramics and Bioactive Glasses in Bone Tissue Engineering: A Review. Polym Rev 58:164-207 . doi: $10.1080 / 15583724.2017 .1332640$

71. Lee S-R, Park H-M, Lim H, et al (2002) Microstructure, tensile properties, and biodegradability of aliphatic polyester/clay nanocomposites. Polymer 43:2495-2500 . doi: 10.1016/S0032-3861(02)00012-5

72. Chang J-H, An YU, Sur GS (2003) Poly(lactic acid) nanocomposites with various organoclays. I. Thermomechanical properties, morphology, and gas permeability. J Polym Sci Part B Polym Phys 41:94-103 . doi: 10.1002/polb.10349

73. Sorrentino A, Gorrasi G, Vittoria V (2007) Potential perspectives of bio-nanocomposites for food packaging applications. Trends Food Sci Technol 18:84-95 . doi: 10.1016/j.tifs.2006.09.004

74. Rydz J, Sikorska W, Kyulavska M, Christova D (2014) Polyester-Based (Bio)degradable Polymers as Environmentally Friendly Materials for Sustainable Development. Int J Mol Sci 16:564-596 . doi: 10.3390/ijms 16010564

75. Scott G, Wiles DM (2001) Programmed-life plastics from polyolefins: A new look at Sustainability. Biomacromolecules 2:615-622 . doi: 10.1021/bm010099h

76. Auras RA, Singh SP, Singh JJ (2005) Evaluation of oriented poly(lactide) polymers vs. existing PET and oriented PS for fresh food service containers. Packag Technol Sci 18:207-216 . doi: 10.1002/pts.692

77. Krzemińska D, Neczaj E, Borowski G (2015) ADVANCED OXIDATION PROCESSES FOR FOOD INDUSTRIAL WASTEWATER DECONTAMINATION. J Ecol Eng 16:61-71 . doi: 10.12911/22998993/1858

78. Davis G, Song JH (2006) Biodegradable packaging based on raw materials from crops and their impact on waste management. Ind Crops Prod 23:147-161 . doi: 10.1016/j.indcrop.2005.05.004 
Recent progress in biodegradable polymers and nanocomposite-based packaging materials for sustainable environment

Wroblewska-Krepsztul, Jolanta

Taylor and Francis

Jolanta Wróblewska-Krepsztul, Tomasz Rydzkowski, Gabriel Borowski, et al., Recent progress in biodegradable polymers and nanocomposite-based packaging materials for sustainable environment. International Journal of Polymer Analysis and Characterization, Volume 23, Issue 4, 2018, pp. 383-395

https://doi.org/10.1080/1023666X.2018.1455382

Downloaded from Cranfield Library Services E-Repository 